\title{
Study on Application of Mobile Converting Station on the Construction of Smart Grid
}

\author{
Deyun Wang ${ }^{1}$
}

${ }^{1}$ State Grid Power Supply Company of Dongming County, Cao County, Shandong, 274500

KEYWORDS: Mobile Converting Station; Smart Grid; Grid Construction

\begin{abstract}
In recent years, the relevant standard release also makes high temperature insulation material used in the mobile substation main transformer to the systematization and standardization. Meanwhile, the mobile substation is also gradually to greater capacity and higher voltage level terms. Understanding of the technical and application status of mobile substations, both for China domestic or related to the upgrading of power transmission equipment for the safe operation of power supply enterprises have a positive and practical significance.
\end{abstract}

\section{Introduction}

Mobile substation called in English "fastpower" - Fast dynamic meaning, that is, it can be moved, quick migration, or installed substation; this substation can use the open-switch combination products and transformers, GIS can also be used combined with transformers and other products, and on a flexible vehicle assembly line control system, connected to signal acquisition and control via cable protection, flexible and centralized power facilities built.

From Category, mobile substation can be divided into two major categories of AC and DC, where an AC mobile substation is more common, can be divided into three basic types of power generation type, transmission and distribution type and control type. Wherein generation mobile substation is integrated with the basic components of small generators, step-up transformers and switching equipment is simple to achieve vehicle transportation, quick installation sets such as the use of function; transmission and distribution substation is integrated mobile switching equipment, step-down transformers and other basic components, to achieve the vehicle transmission or substation, distribution integration, to quickly provide power supply can be used directly in the function in which the switching element according to the voltage level, the main wiring and body size, etc., to free choice open switch, PASS and GIS and other types of switches, step-down transformer can be used single or multi-stage step-down, reducing equipment and protection aspects of land, thus the most flexible; mobile substation is controlled with the above two types of integration to provide protection or master station line display, operation and data acquisition and processing functions.

\section{Mobile Substation Characteristics and Application on The Smart Grid}

Mobile substation following unique structural characteristics: 1) functional integration. About to circuit breakers, disconnectors, grounding switches, CT and PT, surge arresters, transformer stations, battery charging unit, as well as monitoring and protection integrated into a compact module; 2) completed in the factory and each module is integrated kinds of testing, inspection, to ensure that 
equipment factory in the available state; 3) the use of proven standard products, reduce design effort; 4) disposed directly within the module "smart secondary" monitoring, protection technology; 5) silicone rubber casing material ; 6) to complete the test, assembly, wiring work in the factory, thus simplifying site installation workload. (2) the following unique advantages of Mobile Substation 1) due to highly integrated devices and reduce the area; 2) with high reliability and practicality; 3) easy to transport, reduce on-site installation time, you can quickly put into use; 4 ) simplify substation arrangement; 5) less maintenance; 6) purchase, operation, maintenance, and other integrated high cost; 7) environmentally friendly, easy to recycle.

It may be a step-down substation, also can be used for power plants (or farms) using booster station may also be a mobile switching station for the convenience of the discussion, the paper system is called mobile substation. Mobile substation can be both permanent vehicle, it may be a combination of temporary car but the module installed in the ground foundations. Thus their use is very extensive. (1) is adapted for the construction of the substation. Water, electricity, roads, railways, airports, docks, construction of development zones and other places more power construction, load, power centralized location changed often, very suitable for the construction of mobile substation power. (2) Power supply suitable as post-disaster reconstruction. Large-scale disasters (such as earthquakes, typhoons, floods, etc.) occurred, often accompanied by large-scale reconstruction, need a lot of temporary power supply point, the victims temporary resettlement sites also need power, mobile substation come in handy. (3) The use of mobile substation mine. For example, multi-location and underground mine power position, with the face forward, we need to follow the substation forward. China's first set of mobile substation (imported) was used in the mining supply. (4) For emergency power supply. When a ground fault occurs substation, mobile substation can be used to quickly restore local power to protect hospitals, public transportation and other public institutions and important places electricity. Mobile substation plays a vital role in improving grid reliability, reduce downtime and reduce the scope of power and so on. Currently mobile substation power grid and power supply bureau used for this purchase.

Western countries, extensive use of mobile substation has a long history, such as Ontario Hydro to use this device for nearly 50 years, it served nearly 30 sets of equipment, half running; Spain using mobile substation time nearly 30 years . Western countries not only use mobile substation as a temporary or emergency power supply, also in new energy projects as a mobile booster station. Western countries in the project development process, attaches great importance to environmental protection requirements as far as possible without damaging the original landscape and vegetation. Spanish investment in Ecuador Manabi Province Montecristi nearby development of photovoltaic power generation project (60 MW), clearly requires the use of a mobile booster station and a mobile switching station. The project booster station voltage rating of $20 / 69 \mathrm{kV}$, two into two. If the traditional GIS Booster Station needs to open up a lot of space, if you use AIS device, the larger site area. Not only disfigure the vegetation covering the high cost of construction investment is also great, so the project uses two sets of $30 \mathrm{MW}$ boost mobile station devices. Two complete sets of interval combination. High voltage transmission lines are within the scope of the project also uses two separate mobile switching station equipment.

\section{Economic and Social Benefits of Mobile Substations Application}

Whatever the type, their common feature is belong to a special design, manufacturing, bulk copy of the possibility to achieve a rare, mainly because of voltage levels and flexible main wiring, resulting in diverse configurations, in currently exist in the initial stage of design complexity, high cost and power stations main wiring simplify integration and other features, styling products cannot move 
closer to the design, but its highly integrated and simple installation characteristics was able to reduce the time cost of power plant construction costs, labor and accounting land costs, the cost of civil engineering part, so as to achieve the overall plant design economy, is still able to receive power users sought after. In addition to the formation of a fixed station, the mobile substation is also the flexibility to build a temporary construction with AC and DC power distribution, so that large-scale construction machinery and other equipment have flexible enough temporary power source; wherein the main connection of the transmission and distribution of mixed use way to make significant savings in the cost of the power source, power and convenience of the one-time construction cost for the use of a lot of construction equipment to provide high-energy feasibility. One form vehicle DC power (battery), etc. are also mobile power supply.

Mobile substation not only has its unique economy, but also to bring some social effects. In the earthquake disaster, for example, stationary power plant disaster area due Language, there is usually some degree of damage, power failure, emergency medical treatment will make the affected areas, drinking water treatment, heating and temporary residents lack effective disaster relief work power source so many injuries and treatment of secondary disasters prevention work cannot be carried out very well; and mobile substations can be arriving in the area in the first time after the restoration of traffic to help quickly restore production and living order in the disaster area, and because of its damping shock structure design, can prevent further aftershocks and other secondary disasters, emergency response plans of local government alternative equipment, and produce great social benefits.

\section{Future Prospects of the Application of Mobile Substation}

China in recent years due to frequent earthquakes and water, drought and other natural disasters, disaster relief emergency plan is usually paramount in the government departments, and our power grid construction, the damage situation $252 \mathrm{kV}$ and above voltage level of the power plant and not serious, $126 \mathrm{kV}$ and below voltage or power plant is usually due to outdated equipment and low-cost lead product quality is difficult to resist the impact of natural disasters, power stations and distribution network terminals appear disaster outage, and more common not quickly restore power conditions; if temporary distribution station can be equipped to achieve monthly or even six months of temporary power distribution, you can achieve good social benefits.

In addition, China is in the stage of steady development of infrastructure, large-scale infrastructure investment projects of state and government also sponsored an orderly manner, many of them need temporary distribution of power demand, if there is a power source to provide flexible, can may provide for the use of some large construction equipment, it can be a useful supplemental power equipped.

Therefore, the future of mobile substation with power in our country, will probably have a more broad prospects for development. In the main terminal versatility on, there may be a certain degree of maturity requirements. Worldwide, the situation of various wars, disasters and complex building construction, etc., will also have a temporary power with demand, in order to meet the energy needs of rapid response force; therefore, the future of mobile substation, may be due to its efficient and flexible suite of features, become a useful supplement world and the region with electricity, and gradually accepted and loved by the user, the potential market demand will continue to appear. Of course, such a product, because of their special custom design and manufacture, to some extent, will increase the difficulty and cost of manufacturing, non-standard design will also make it subject to certain limited extent, but with our electromechanical switches and transformers constantly improve 
the product in the near future, we believe that mobile substation will have made great development space.

\section{Reference:}

[1] Liping Lu, Junxue Geng. School of Computer Science and Engineering, Xi'an Technological University, Xi'an 710032,China Tianren Zhao Dongguan Gaoneng Electric Co., Ltd No.2 Jinhui Road Dongguang Guangdong 523012,China. Research and Analysis Small Infrared Object Detection Track Algorithm and Its Image Processing Technology [A]. Proceedings of 2012 3rd International Conference on Computer Research and Development(ICCRD 2012) VOL.02. 2012.

[2] Zhang Ning. Lv Jian Zhou. Yun Wu. g State Key Laboratory of Electronic Thin Films and Integrated Devices, School of Optoelectronic Information, University of Electronic Science and Technology of China (UESTC),Chengdu 610054,China. Research on Infrared Imaging System of UIRFPA Based on Virtual Instrument [A]. Proceedings of IEEE 2012 10th International Conference on Electronic Measurement \& Instruments (ICEMI’2012) VOL.02. 2012.

[3] Yao Yunping Zhang Wei. University of Electronic Science and Technology of China, Chengdu 611731,China. An Infrared Small and Dim Target Detection Algorithm Based on the Mask Image [A]. Proceedings of IEEE 2012 10th International Conference on Electronic Measurement \& Instruments(ICEMI'2012) VOL.04 [C]. 2012.

[4] Yuqing He, Feihu Liu. Key Laboratory of Photo electronic Imaging Technology and System, Ministry of Education of China, School of Optoelectronics, Beijing Institute of Technology,Beijing,China,100081. Counter sniper: a localization system based on dual thermal image. Proceedings of Conference 7850 Optoelectronic Imaging and Multimedia Technologies. 2010. 